\title{
Notes on the vocalizations of Plain-tailed Wren (Thryothorus euophrys)
}

\section{Peter Boesman}

In the following we briefly analyze and compare voice of the different races of Plain-tailed Wren (Thryothorus euophrys). We also try to quantify the extent of any vocal differences using the criteria proposed by Tobias et al. (2010), as a support for taxonomic review. We have made use of sound recordings available on-line from Xeno Canto (XC).

\section{Comparison of songs with sonograms:}
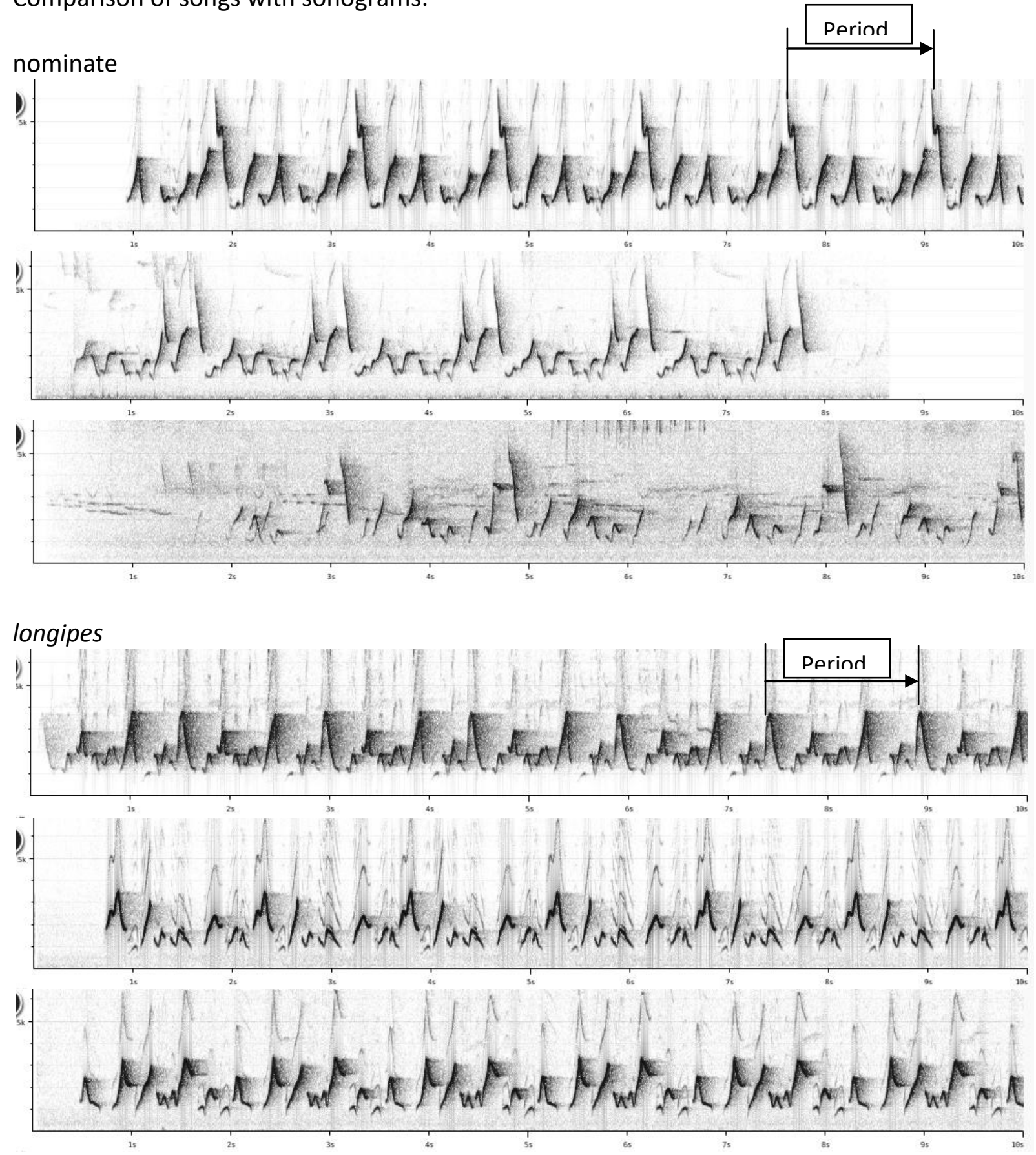


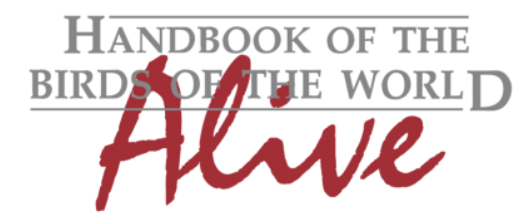

\section{ORNITHOLOGICAL NOTES}
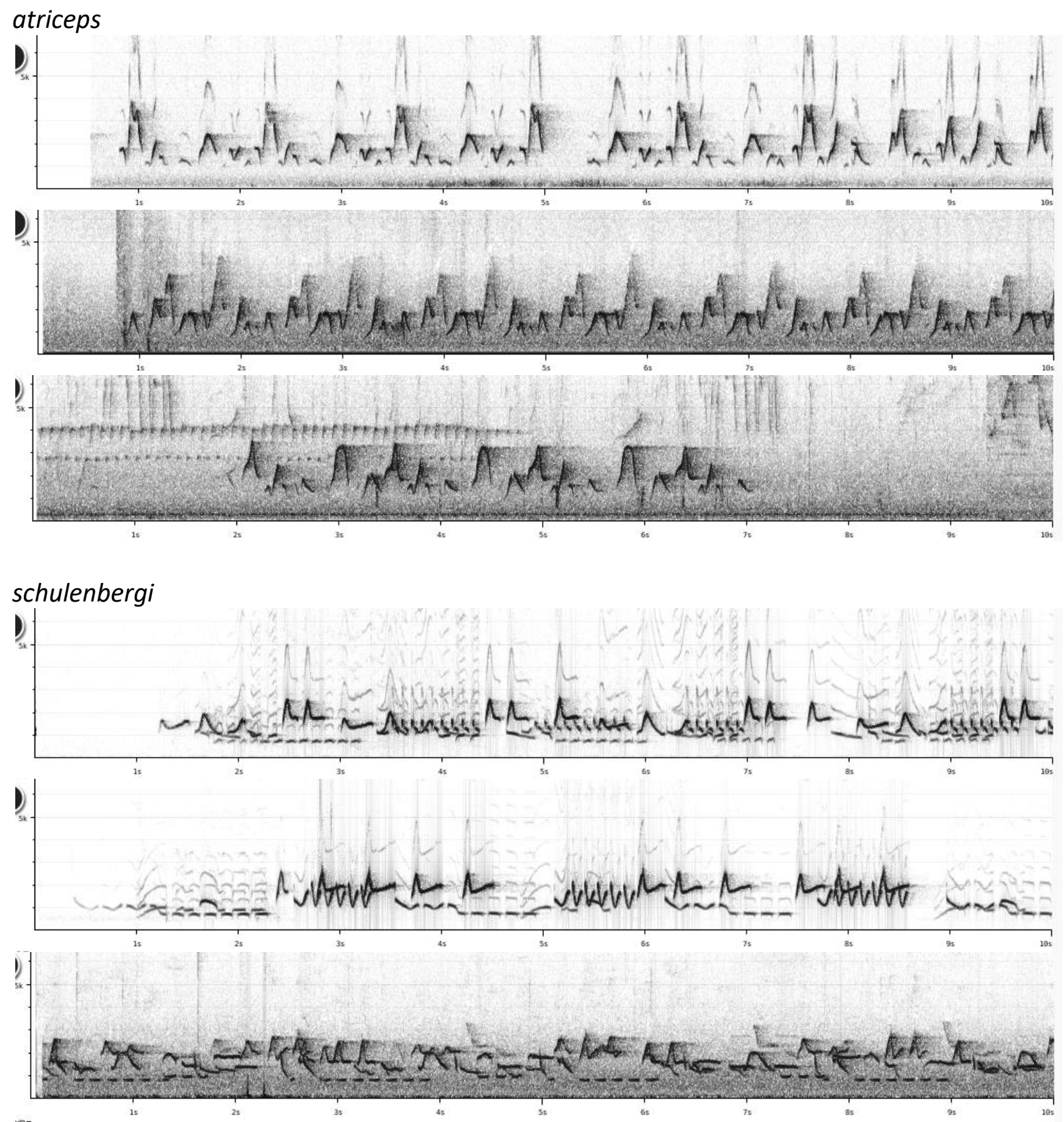

From the above sonograms it is clear that vocally one can identify three groups:

longipes and atriceps have near identical duet songs, with very similar note shapes. Duets are perfectly synchronous, with period length of full phrase of notes about 1.5-1.7s.

nominate has a similar synchronous duet with similar duration of a full phrase (period), but includes a sharply downslurred note covering a wide frequency range (coming down from c. $6 \mathrm{kHz}$, well above the max. frequency in duet of longipes/atriceps), possibly uttered by the female bird (score 3).

Most distinctive however is song of schulenbergi. It is an asynchronous duet of two or more birds ('group duet'?), with some notes at very low flat pitch (it is quite amazing to listen to !). 

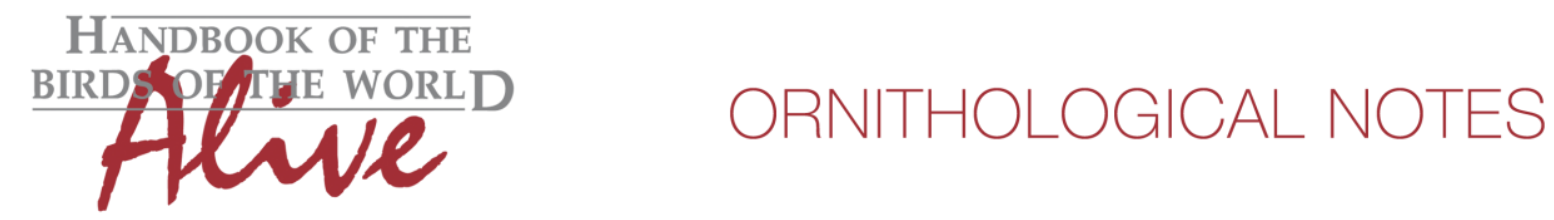

schulenbergi vs. longipes/atriceps: quantification of vocal difference based on max. freq. (schulenbergi below $3 \mathrm{kHz}$, score 2), note shapes (e.g. flat-pitched notes, 1-2) and asynchronous duet (reflected by pace or max. number of simultaneous notes at a single point in time, score 3 ). When applying Tobias criteria, this would lead to a total vocal score of 5.

schulenbergi vs. nominate: quantification of vocal difference based on max. freq. (schulenbergi below $3 \mathrm{kHz}$, score 3), note shapes (e.g. flat-pitched notes, 1-2) and asynchronous duet (reflected by pace or max. number of simultaneous notes at a single point in time, score 3). When applying Tobias criteria, this would lead to a total vocal score of 6.

As a final note, the undescribed taxon known as 'Mantaro Wren' from the Huancayo area in C Peru, has the following song:

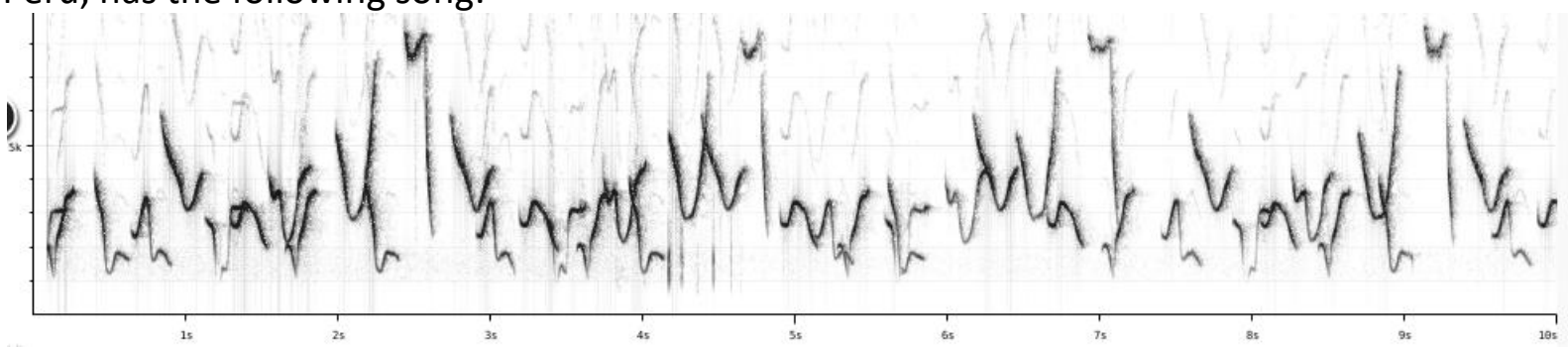

It has the highest pitched song compared to above groups. Given that some notes exceed $8 \mathrm{kHz}$ and the closest race schulenbergi with its low-pitched song is exactly the opposite, this is clearly not a clinal change in voice. Duet is asynchronous but both members seem to utter periodically repeated phrases (unlike schulenbergi), with a phrase period of slightly more than 2 s. Based on max. freq. and phrase period a.o., a score of about 5 vs. the above groups seems likely.

This note was finalized on 15th April 2016, using sound recordings available on-line at that moment. We would like to thank in particular the many sound recordists who placed their recordings for this species on XC.

\section{References}

Tobias, J.A., Seddon, N., Spottiswoode, C.N., Pilgrim, J.D., Fishpool, L.D.C. \& Collar, N.J. (2010). Quantitative criteria for species delimitation. Ibis 152(4): 724-746.

\section{Recommended citation}

Boesman, P. (2016). Notes on the vocalizations of Plain-tailed Wren (Thryothorus euophrys). HBW Alive Ornithological Note 290. In: Handbook of the Birds of the World Alive. Lynx Edicions, Barcelona. (retrieved from http://www.hbw.com/node/1251734 on 12 October 2016). 